\title{
The impact of transport management on the local activities system: the role of limited traffic zones
}

\author{
L. Biggiero \\ Department of Civil, Building and Environmental Engineering, \\ University Federico II of Naples, Italy
}

\begin{abstract}
The impacts of transportation in planning land use and activities are not always intended and can have unforeseen or unintended consequences such as congestion or evident impacts on the local economy where the interventions are conceived. This is the case for Limited Traffic Zones (LTZs), i.e. areas where cars are not allowed in them. In this paper, the impact of these measures on the local economy is analysed, considering as a case study the town of Napoli in the south of Italy, where two Limited Traffic Zones, in two different boroughs and years, named Vomero and Chiaia, have been introduced. Moreover, the impacts due to changes involving one of the LTZ's areas are also observed and analysed through a before-after survey. The direct impact on traffic congestion has not been taken into account. More than $30 \%$ of all activities have been interviewed in the two restricted areas and some key points have been assessed for the successful or unsuccessful of car restriction measure. Retailers were also asked about their decrease in turnover in order to evaluate the effects of the LTZ's area after taking into account the actual economic crisis. The survey showed how much the retailers require: efficient public transport; parking places as close as possible; residential and activity density and typology. Those are the main reasons for the success of the Vomero LTZ zone and of the failure of the Chaia restricted zone. Other revealed indicators gathered in the survey confirmed the results underlying the attractiveness of the subzone of Chiaia that is a string of restaurants close to the seafront.
\end{abstract}

Keywords: limited traffic zones, impacts on local economy, local public transport accessibility. 


\section{Introduction}

An approach for viewing the economic impacts of investments in public transportation today and in the future is described in the report of Weisbrod and Reno [1]. Indeed they say "Transportation investment affects the economy through two fundamental mechanisms: (1) impacts of spending - the act of investing money in public transportation facilities and operations supports jobs and income for that industry, as well as jobs and income in supplier industries and other affected elements of the economy; (2) costs and productivity impacts the public transportation services that are enabled by that investment provide enhanced mobility, time and cost savings; leading to broader economic growth occurs as a result of changes in disposable household income, business productivity and market access".

Longer-term travel benefits are a fundamental justification for public transportation investment that can ultimately lead to greater and more lasting impacts on an area's economy. Direct benefits for travellers fall into four core categories: (1) travel time savings, (2) travel cost savings, (3) reliability improvements and (4) safety improvements. All the types of benefits can provide monetary savings for both public transportation passengers and for travelers who continue to use other transportation modes [2].

Some of the travel-related impacts translate directly into economic impacts (e.g., cost savings to households and businesses). Other travel related impacts lead to economic impacts through additional factors (e.g., effects of worker schedule reliability on business productivity). Both types also lead to shifts in purchasing patterns and business expansion decisions [3-5].

Improvements in public transportation services may lead to economic productivity changes as a consequence of both expanded public transportation service and reduced traffic congestion. This may specifically include:

- Mobility and market access - business productivity benefits from access to a broader and more diverse labour market with a better fit of workers skills, and access to a wider customer market;

- Spatial agglomeration economies - business productivity benefits from agglomeration or clustering of similar and complementary activities, enabled by public transportation services and terminal facilities.

In general, the main objective of these investments is that of attracting the transport modes of eco-mobility giving restrictions on the individual car-use. Among the measures with push effects, there are car limited zones, permanent or time-of-the-day car bans, speed reductions, road pricing, etc. Among the measures with pull effects, there are buses and trams lanes, park and ride, bike and ride, car sharing, car pooling, etc. Measures combing both push and pull effects are redistribution of carriageway space to provide cycle lanes, broader pavements, bus lanes, redistribution of time-cycles of traffic lights in favour of public transport and non-motorized modes. In classical transportation planning the focus was on hard measures which are more infrastructure-orientated. Within the last years soft policies for the government of urban mobility have gained in importance such as information, communication and coordination [6, 7]. 
Integrating networks and services increase the public transport use; it follows a reduction in the use of car; a reduction in the air pollution and noise and better life conditions [8].

Among the push measures, limited traffic areas have been introduced in most of the historical centres of towns all around the world with the aim of increasing pedestrian areas, commercial activities, and reducing pollution to preserve historical sites. Many access restriction schemes are already in operation throughout Europe and in some cases the differences among them can represent an obstacle to travellers for moving around.

In these areas, only specific vehicles are allowed to drive, such as buses, police cars, ambulances and, of course, residents have access as well. All of the "authorized" vehicles have their license plate registered with the Municipal Police. If a vehicle crosses a limited traffic area, cameras will take a picture of the license plate. The photo is automatically sent back to a computer of the Municipal Police and if the license plate is not registered a violation ticket is generated and sent to the owner of the vehicle.

In Italy these limited zones have been often put in place in order to reduce congestion and pollution, thus making city centres more pleasant for residents and visitors alike. Each zone has its own regulation: some are restricted to certain hours; some are permitted to residents only or to some vehicles. These conditions are exhibited underneath the road sign which marks the entrance to the zone. Although the sign is an international driving sign, it is one that some countries do not use, and a significant proportion of motorists are not familiar with it. In Italy these areas are better known as ZTL (Zona a Traffico Limitato Limited Traffic Zone (LTZ)).

Following the trend of many Italian towns like Milano, Roma, Firenze, also Napoli, in the south of Italy, has recently experienced this measure. Some car limited zones were introduced in different periods of time. The first was in the historical centre; the second in the borough of Vomero and in the last years in the boroughs of Chiaia and Soccavo. Moreover, the first LTZ was enlarged including other adjacent areas. In this study two car limited zones have been considered to understand success and failure factors analysing economic impacts on retailers. The first one is in the Vomero borough, while the other one in the Chiaia borough. The result was very different in the two cases. The reason of this different "behaviour" probably lies in the different size and shape of the restricted area and the typology of shops. Investigations on this will be supported by proper surveys carried out in the two areas, taking also into account changes of market segments in the first area stressing the relationship among restricted access areas and the activity system. Since Chiaia LTZ has been partially suspended, a second survey has been carried out to perform a before-after analysis.

The paper is organised as follows. In section 2, the two Limited Traffic Zones are described, while in section 3 the results of the survey are reported. Conclusions and further perspectives are described in section 4 . 


\section{The limited traffic zones in Naples}

Napoli is in the south of Italy and its historical city centre is one of the largest in Europe, covering 1,700 hectares. It is listed by UNESCO as a World Heritage Site. It is s made up of 32 boroughs, among them Vomero and Chiaia. Vomero is a hilly and heavily urbanized area in the center of Napoli. It is a residential zone developed at the end of the $19^{\text {th }}$ century up to the First World War as a rural zone for the vacation of the upper middle class of the city. During this period numerous dwellings were built along two primary roads, via Scarlatti and via Giordano, and around them, including villas in the late Art Nouveau style. Two funiculars were built named "Chiaia" and "Montesanto" linking Vomero with Chiaia borough and with the ancient city centre. Between the two world wars also the third funicular, named "Centrale", was realised. During the second part of the $20^{\text {th }}$ century this area knew a dramatic increase of residential housing for the middle class with a heavy urbanization made without any master plan leading to a high population density and traffic congestion. The new underground rail system, operating from the last decade of the past century, has contributed to speed up the public transport system and to reduce traffic congestion. In the last few years the underground has been extended up to the central station.

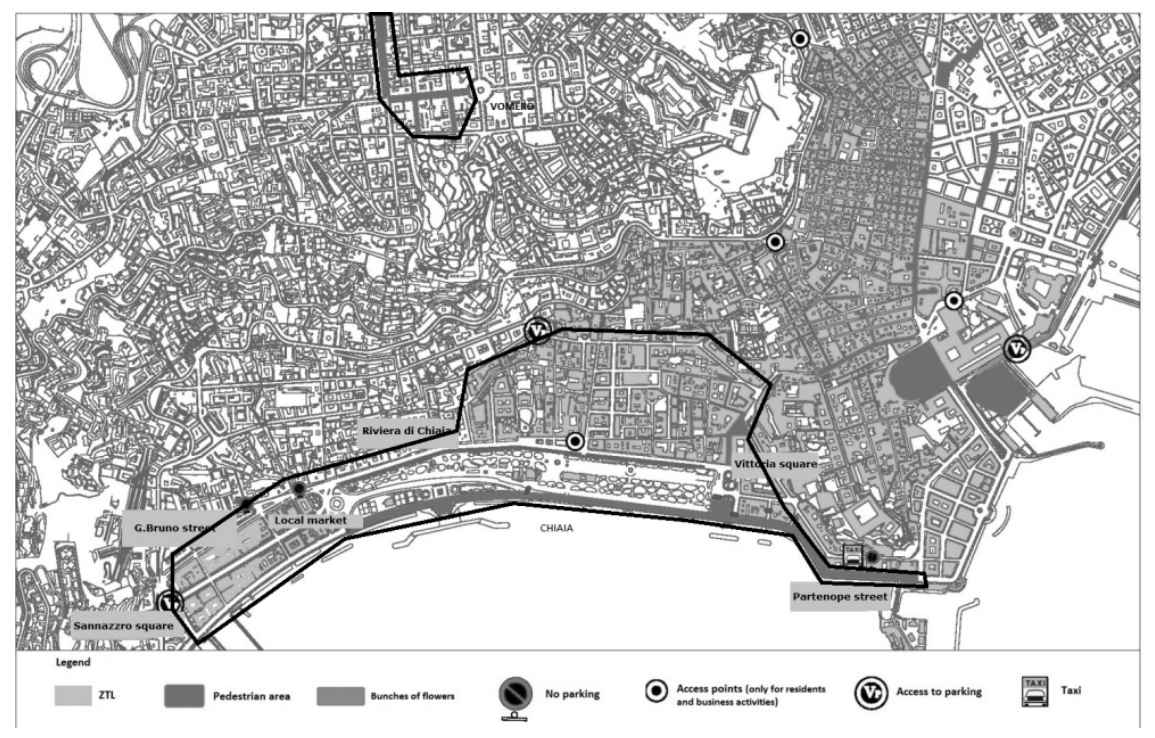

Figure 1: The limited traffic zones of Chiaia and Vomero in Naples.

Chiaia is placed along the seaside and it is considered to be one of the "posh" boroughs together with that of Posillipo. It was built from the $18^{\text {th }}$ and the $19^{\text {th }}$ century initially from a spontaneous expansion outside the historical walls of the city and then following a plan for housing which included and rearranged the 
previous buildings. Many noble dwelling of historical interest are present in it together with more ancient churches. The most prominent landmark in the area is the large public park known as the Villa Comunale, born as the royal garden along the seaside, including the second oldest aquarium in Europe. Chiaia has become one of the main centres for shopping in Italy and collects the world's most famous brands and some of the shops historically the most important of the city at an international level, such as the famous tie shop "Marinella". Due to the closeness to the seaside, it has an elongated form and can be divided into three different sub-boroughs with different economic level and land use. The first, on the right side of the map, is the shopping centre; the second, in the middle, is mainly residential; the third, on the left side, has a lower economic level, in the average, and include a local market mainly for food. Moreover, on the border of the right side of the map there is a sort of restaurant district, on the seaside.

Chiaia is connected by the metro line 2 and many buses lines.

\subsection{The Vomero LTZ}

In the mid nineties of the last century Scarlatti Street was closed to cars and allowed only to pedestrians, becoming very busy thanks to the closeness to the Vanvitelli metro station of Line 1. The pedestrian area was extended in 2008 also to part of the close Luca Giordano street and the actual situation is the one reported in Fig. 1 since the Limited Traffic Zone was expanded in October 2010 to the whole Giordano street. The LTZ is active every day from 10:00 a.m. to 14.00 p.m. and from 16:00 to $22: 00 \mathrm{pm}$ while Scarlatti Street is always for pedestrians.

The Scarlatti LTZ was the first car restricted shopping area defined in Naples.

After a first period of heavy protests, the retailers agreed since consumers, after a short period of dropping, significantly increased. For this reason the enlargement of the LTZ was considered and realised as above described. The farthest points of the LTZ has a distance of 700 meters and almost all the LTZ area has distance less than 600 meters from the metro station and from the funiculars of Chiaia and Centrale. No parking areas are available next to LTZ and free parking slots are hard to find but a large number of garages are distributed around, often with high hourly fares.

\subsection{The Chiaia LTZ}

In the Chiaia borough an LTZ was previously adopted covering the area which includes the shops of the world's most famous brands. In the year 2012 Napoli hosted the America's Cup competition from the 7th to the 15th of April. So the local authority decided to introduce a new LTZ in the city centre called "exceptional" starting from the 26th of March till the 25th of April.

Caracciolo and Dohrn streets were restricted to cars and partially to pedestrians to allow the preparation of the technical area to support sailors. The first street represents the promenade of the town from where citizens could see the competition and the beautiful view of the Gulf of Napoli. Along Riviera di Chiaia Street, parallel to Caracciolo Street on the opposite site of the Villa 
Comunale, transit was allowed to residents, special vehicles such as police and ambulance, vehicles to load and unload freight. The LTZ operated from 7:00 a.m. until 20:00 p.m. (including Saturdays and Sundays). Public transport was improved with the introduction of a bus operating within the LTZ every 7-8 minutes called the "Chiaia Tender Bus". The frequency of other buses passing through the area and connecting other boroughs of the city was improved together with the frequency of metro lines operating in the same area. When the competition ended, the LTZ was extended till the end of May 2012 from 7:00 a.m. till 18:00 p.m., but with a more restricted area, i.e. some streets were opened to cars, while the promenade was opened only to pedestrians.

This LTZ contributed apparently to the decrease of traffic flows within it, but the congestion induced on the boarding roads was extremely high. Moreover, retailers and restaurateurs registered a drop of consumers and therefore of sales and lots of protests were carried out.

A partial collapse of a historical building on the Riviera di Chiaia Street in March 2013 compelled the local authority to suspend the LTZ and re-define it opening to car some pedestrianized roads. In particular, Caracciolo Street has been almost all opened as a two way road and Riviera di Chiaia Street has been used as a parking area. The part of Riviera di Chiaia Street beyond the collapsed building was practically isolated from relevant traffic flows. The position of this building can be seen on the map in Fig. 1, just above the great roundabout, which is visible on the centre-left side of the Chiaia LTZ.

The farthest points of Chiaia LTZ have a pedestrian distance of 2700 meters and only a part of the LTZ is included in a circle of 650 meters centred on the two metro stations of "Mergellina" and "Piazza Amedeo" of the line 2. A parking area is present near the seaside in "Viale Dohrn" (Villa Comunale) but its distance from shops areas is more than 1000 meters. Also around LTZ, free parking slots are hard to find and the garages present high hourly fares.

\section{The surveys}

The first sample is made up of 150 activities half in Chiaia and half in Vomero. Activities have been classified according to the Census classification. In the LTZ of Chiaia the number of interviewed activities is 75 on the 193 present with a sample rate of $39 \%$. Also in the LTZ of Vomero the number of interviewed activities is 75 but the present activities are 225 with a sample rate of $33 \%$. In both cases the accuracy is about of $7 \%$ assuming an interval of confidence of about $85 \%$.

A unique case in this survey is represented by Partenope Street in Chaia, since $94 \%$ of the present activities are represented by restaurants; therefore this area deserves a separate analysis.

An evident difference between the two LTZ is in the distribution of the activities as shown in Fig. 2: in Chiaia more than $40 \%$ of the activities are represented by food and drinks activities, bars and restaurants, and also a local market is present; in Vomero the main activities are clothes and shoes which represent the $55 \%$ of the total. 
Confirmation of this can be seen in the number of bags, proportional to the sold goods, with which consumers leave shops: in Chiaia is between 2 and 4 while in Vomero is less than 2 in the average. This explains why in Chiaia $76 \%$ of the retailers perceive as indispensable the use of car while in Vomero the percentage is lower $(52 \%)$. Such perception is primarily due to some typical aspects of the two LTZs. One is relative to the extension of the area and another to the accessibility to public transport.

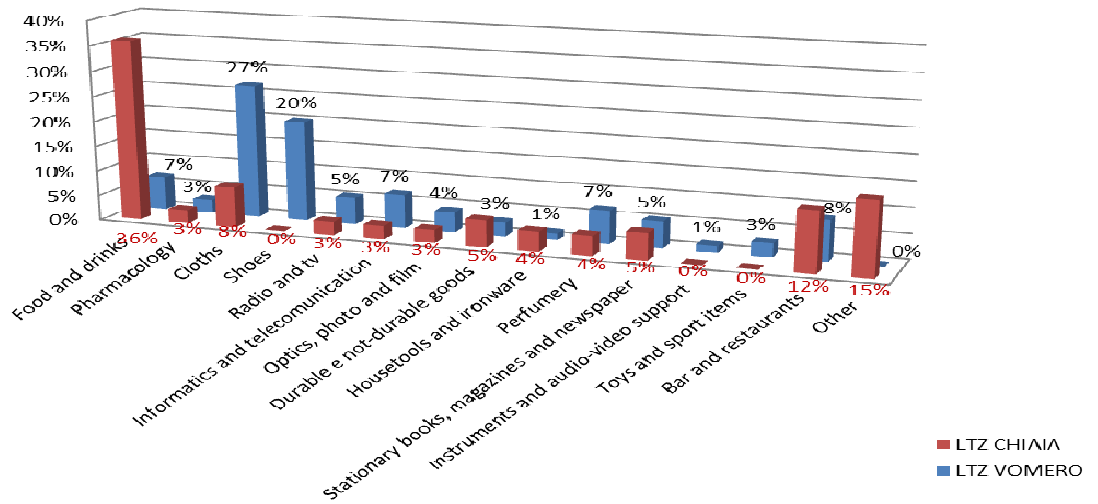

Figure 2: A comparison among activities per typology between the two LTZs.

The Vomero borough has a large number of residents with a high population density. Thus the pedestrian area can be reached from a large number of people simply by walking. This leads to few sold goods (few bags) but to a higher frequency of selling. Moreover, the high accessibility to public transport, such as metro and funiculars $[7,8]$, increases the influences of the area to all the people close to the stations out of Vomero. Only the $55 \%$ of retailers perceive public transport as unreliable.

On the contrary, Chiaia borough has a lower population density and the non homogeneous distribution of the typology of shops forces people to cover longer distances. Since the public transport is based on bus lines which are perceived as unreliable by the $100 \%$ of interviewed, car is considered as essential.

The impacts on local economy of the quality of the transport facilities supporting LTZ areas can also be deduced in the declared variation of the annual turnover of the retailers reported in Table 1. Since the survey has been carried out during the economic crisis, it can be expected a general reduction of the retailers' turnover. Indeed in Chiaia all the interviewed retailers perceived a relevant decrease in the turnover. A quarter of them declared a reduction greater than $60 \%$ and an half of them between 30 and $60 \%$. Concerning the Vomero LTZ, only the $65 \%$ of the retailers perceive a reduction and most of them (57\%) estimate it as being between $10 \%$ and $30 \%$. Most likely, this is the real effect of the crisis. The comparison between Vomero and Chiaia LTZ clearly shows that 
the crisis in Chiaia LTZ cannot be completely ascribed to the European and national economic crisis but there is a relevant effect due to the new LTZ. Since in Chiaia public transport is perceived as unreliable, retailer were asked about how useful they consider the large parking area of Viale Dohrn. All of them judge such parking area as totally un-useful beneath car is considered essential.

The effect of LTZ on the activities of Partenope Street is not negative. This is due to the particular location of the restaurants, on the pedestrian part of the promenade, which is highly attractive especially during the spring-summer period. Indeed, during this period all the restaurants declared their revenues as increased; in the autumn-winter period $67 \%$ of them declared a reduction. An increase of delivering time has been perceived by most of restaurant $67 \%$ and all of them consider the car as essential to reach their place.

A second survey has been carried out to understand the benefits arisen from the new traffic scheme consequent to the collapse of a building on the Riviera di Chiaia Street. 68 retailers have been interviewed corresponding to the $40 \%$ of the activities since the total number of activities has decreased because some of them closed their business for their closeness to the collapsed building since no safety can be certified in these shops. Such "after" sample shows only marginal differences with respect to the "before" one. The differences can be ascribed both to general economic crisis and to the transport management relative to the LTZ. Indeed the percentage of retailers which perceive a high decrease of the turnover has increased and the number of bags has decreased in the average. Most of retailers suppose that many customers which used the Caracciolo Street corridor to go to work in the CBD before the LTZ introduction, have changed their route and thus the place for shopping. These customers are resident in the hilly borough of Posillipo which is served by only one bus line having a low frequency. Car is essential for them and thus for retailers. We expected such customers to return on the previous route once Caracciolo Street has been opened to cars, but it didn't happen probably due to the congestion of Caracciolo Street caused by the reduced capacity. Only two lanes in each direction are available with respect to the four lanes adopted before the first introduction of the LTZ.

Table 1: Perception of a decrease in the turnover.

\begin{tabular}{|l|l|l|l|l|l|}
\hline & $\begin{array}{l}\text { Not } \\
\text { revealed }\end{array}$ & Revealed & $10-30 \%$ & $30-60 \%$ & $60-100 \%$ \\
\hline Vomero & $35 \%$ & $65 \%$ & $57 \%$ & $39 \%$ & $4 \%$ \\
\hline Chiaia before & $0 \%$ & $100 \%$ & $28 \%$ & $48 \%$ & $24 \%$ \\
\hline Chiaia after & $0 \%$ & $100 \%$ & $6 \%$ & $49 \%$ & $53 \%$ \\
\hline
\end{tabular}

\section{Conclusions}

At this time of economic problems in many countries in Europe, governments are searching for ways to create employment and boost the economy and in a Keynesian vision many look to investment in transport infrastructure to do this. 
But if employment benefits are evident soon, not always results have been achieved in a long term view. It often happens when investments haven't a vision of the entire economic system [7]. Concerning traffic flows, the Braess paradox is a simple example of the failure of a new infrastructure. So if the basic theory states that investments in transport schemes will cut travel times and improve reliability, increase accessibility, and as a result industry will become more efficient, labour markets will become bigger, and the economy will grow, this is not always true. The case study of town of Napoli is interesting in this respect since the same intervention, i.e. the introduction of a LTZ, in two very different boroughs has brought to different impacts on the local economy. In case of Chiaia there has been a decrease of the turnover; single is the case of Partenope Street which has deserved a separate analysis. On the other hand, an increase of the turnover has been registered in the Vomero borough. The main motivation of this different impact can be explained on the basis of the different nature of the boroughs and the accessibility to a reliable public transport. In this period of crisis, seems to be more important to invest on the public transport. But few funds are available therefore only policies of re-planning of the public transport services are possible $[9,12]$ both with push measures to reduce car use such as parking fares and LTZ introduction $[10,11]$. The survey described in this paper clearly shows how relevant is the role of transport accessibility, both public and private, for the economic success of a measure such as a limited traffic zone. Indeed, transport should be designed depending of the economic characteristics of the borough which LTZ will be placed in. Vomero borough which has a homogeneous high residential density, shops mainly for clothes and shoes and is strongly congested, can host a LTZ only if served by a reliable and frequent public transport, typically consisting of rail systems which economic, effects have already described in literature $[8,13]$. Probably due to the particular shape and to the different sub-borough, Chiaia needs a system of measures regarding both public and private transport. The shopping sub-borough is attainable by the metro line 2 and the Chiaia funicular which are on the boundary of the area, that is some shops have a distance more than 600 meters from the station. Two new stations of the metro line 6 will be realised in the coming years closer to the centre of the shopping sub-borough. On the contrary, the Chiaia sub-borough dedicated to local market and food activities, as previously described in the introduction, presents the only metro station of Mergellina which is far from the local market. Thus beneath car is essential due to the number and the weight of bags, no close parking area is available.

These surveys has clearly shown the economic impacts of a typical traffic measure, such as the LTZ introduction, aimed at improving the quality of life in an area. The result of the surveys is clear: if in the short term impacts can be similar for the residents, in the mid-long term unforeseen economic impacts on retailers can completely upset the area. A local drop of the economy implies the closure of shops and then the area becomes less safe for people, which is opposite to the purpose of a LTZ. For this reason a LTZ cannot be considered as only a simple traffic calmer or a pollution reduction measure; on the contrary it should be designed after a deep study of its possible interactions with the 
economical asset of the area. And the only way to moderate its impacts or improve the quality of life is to support it with an effective and reliable public transport service and/or capable parking areas close to the LTZ. LTZs should not be considered as an independent push measure, but should be included in an urban and transport master plan.

\section{References}

[1] Weisbrod, G. \& Reno, A., Economic impact of public transportation investment, report prepared as part of the Transit Cooperative Research Programme project, J-11, task 7, 2009.

[2] Cambridge Systematics, Measuring and Valuing Transit Benefits and Disbenefits, TCRP Report 20, 1996.

[3] EcoNorthwest, Estimating the Benefits and Costs of Public Transit Projects: A Guidebook for Practitioners, TCRP Report 78, 2002.

[4] Weisbrod, G., Current Practices for Assessing Economic Development Impacts from Transportation Investments, NCHRP Synthesis 290, 2000.

[5] Pagliara, F., Delaplace, M. \& Vassallo, J.M., High-speed train and tourists: what is the link? Evidence from the French and the Spanish capitals, WIT Transactions on the Built Environment, 138, 2014.

[6] Henkel, A. \& Haag, M., Sustainable mobility in cities: reducing the carbon footprint of transportation in tübingen. Proceedings of Real Corp, Wien, 18-20 May, 2010.

[7] Cascetta, E., Pagliara, F. \& Papola, A., Governance of urban mobility: complex systems and integrated policies, Advances in Complex Systems, 10, pp. 339-354, 2007.

[8] Cascetta, E. \& Pagliara, F., Integrated Railways-based Policies: The Regional Metro System project of Naples and Campania, Transport Policy, 2, pp. 81-93, 2008.

[9] D’Acierno, L., Gallo, M., Biggiero, L. \& Montella, B., Re-planning public transport services in the case of budget reductions. WIT Transactions on the Built Environment, 138, 2014.

[10] D’Acierno, L., Ciccarelli, R., Montella, B. \& Gallo, M., A multimodal multiuser approach for analysing pricing policies in urban contexts. Journal of Applied Sciences, 11(4), pp. 599-609, 2011.

[11] Gallo, M., D’Acierno, L. \& Montella, B., A multimodal approach to bus frequency design. WIT Transactions on the Built Environment, 116, pp. 193-204, 2011.

[12] Gallo, M., Montella, B. \& D'Acierno, L., The transit network design problem with elastic demand and internalisation of external costs: An application to rail frequency optimisation. Transportation Research Part C, 19(6), pp. 1276-1305, 2011.

[13] Pagliara, F \& Papa, E., Urban rail systems investments: an analysis of the impacts on property values and residents' location, Journal of Transport Geography, 19, pp. 200-211, 2011. 